\title{
A Comparative Appraisal of Quality of Life (QOL) of Aged Living with Sons and Living with Daughters
}

\author{
Sarita Saini* and Sushma Jaswal** \\ Department of Human Development and Sociology, Punjab Agricultural University, \\ Ludhiana 141 004, Punjab, India \\ E-mail: *<sarita4040@yahoo.com>, **<sushma.jaswal@gmail.com>
}

KEYWORDS Quality of Life. Support systems. Dimensions of QOL. Aged

\begin{abstract}
The present study was undertaken during 2006 for a comparative appraisal of quality of life of aged (65 years and above) living under two support systems, i.e. living with sons and living with daughters. The study was based upon the sample of 200 subjects from Ludhiana city, equally drawn from the two support systems. The sample drawn from each support system was further subdivided into two socio-economic groups which were further subdivided over two sexes. A Quality of Life Profile, Senior's version prepared and published by Quality of Life Research Unit, University of Toronto, Canada (2000) was administered for comparative appraisal of Quality of Life (QOL) of the subjects under selected support systems. The results revealed significant differences in the quality of life of aged living under the two support systems. It was found that the aged living with sons had better Quality of Life. Also, the aged were found to have lower QOL for the other support system i.e. "Living with daughters". Co-residence with sons was found to be the foremost choice of the aged irrespective of age, sex, marital status and education.
\end{abstract}

\section{INTRODUCTION}

Across the world, countries are experiencing population ageing. The growth rate of the elderly population is more rapid in developing countries like India than developed countries. India had 12 million old in 1901, 56 million in the year 1991 which increased to 71 million in 2001 , is suspected to have crossed 100 million by now and is expected to reach 177 million by 2025.Apart from demographic transitions; socio-economic and political changes together with increased individualism have altered living conditions of the elderly. Many face isolation and lack the resources for a better quality of life. Today, the aged not only demand that society should ensure their independence and participation, but also grant them a life full of care, fulfillment and dignity. But a limited understanding of factors influencing their quality of life is largely responsible for the elderly being denied a dignified existence. After all, the last stage of life holds as much potential for growth and development as earlier stages. The diversity among the elderly and varied inter-related influencing aspects from their environment need significant consideration of researchers and policy planners.

As the ageing of population is becoming more and more pronounced, the concern for the quality of life and well- being of the older people is also growing in both developing and developed countries. The conventional view is that there is direct positive relationship between QOL and quality of human beings. A higher quality of life improves the quality of the individual in a mutually self-reinforcing manner. Also, the care and QOL are important determinants of longevity. Amos et al. (1982) hypothesized that people of poorly developed regions are content with less because they aspire for less. Ramamurthi and Jamuna (1993a) observed that self-acceptance of aging changes, self-perception of health and satisfaction, with marital and familial relations are some of the factors that predict life satisfaction among the elderly and also explain the phenomenon of loneliness.

In the developing countries, the family remains the mainstay of care and support to the old persons, where social security systems are generally inadequate (United Nations, 1994). Family support is particularly crucial in the case of the oldest of old, whose physical and economic needs are usually greater (United Nations, 2002). Living arrangement of the aged people with the members of the family is very essential for a satisfactory life on account of the stronger emotional bonding of the parents with their children. That is why, it is a social expectation in India that the adult son(s) take care of the aged parents and the daughter(s) take charge of the parents only if the aged did not have son(s) (Vatuk 1990)). 
Also, the studies conducted in Delhi and Lucknow showed that majority of the elderly living with their sons was partially or wholly dependent upon them (Delhi School of Social Work 1977; Soodan 1982). In view of the foregoing, it was considered logical to direct investigations towards a comparative appraisal of quality of life of the aged living under two support systems i.e. "Living with sons" and "Living with daughters".

\section{MATERIALS AND METHODS}

The present study was undertaken to assess the Quality of Life of the aged (65 years and above) living under two support systems, i.e. Living with sons and Living with daughters. The study was based upon a sample of 200 subjects from Ludhiana city, equally drawn through simple random sampling from the two support systems (Fig.1). The sample drawn from each support system was further subdivided into two socio-economic groups namely Middle SocioEconomic Group (MSEG) and Lower Socio-Economic Group (LSEG). Which were further subdivided over two sexes. A Quality of Life Profile, Senior's version prepared and published by
Quality of Life Research Unit, University of Toronto, Canada (2000) was administered to measure the Quality of Life (QOL) of the subjects across these two support systems. This measure of Quality of life is culture fair. For comparative appraisal of QOL of the aged across these two support systems Z-test and t-test were employed.

The tool employed for this study provides a holistic insight into the different components and dimensions of the Quality of Life (Fig.2). It expresses QOL in the quantitative terms through appropriate indices.

\section{RESULTSAND DISCUSSION}

\section{Background Information of the Aged across Two Support Systems}

Table 1 shows the distribution of aged males across two support systems with reference to age, socio-economic status, education, marital status, living arrangement (with or without spouse) and number of children.

Majority $(68 \%)$ of the male respondents in this study were in the age group of $65-77$ years, with only few $(8 \%)$ being above 89 years of

\begin{tabular}{|c|c|c|c|c|c|c|c|}
\hline \multicolumn{8}{|c|}{ Total Sample (200) } \\
\hline \multicolumn{4}{|c|}{ Aged living with Sons (100) } & \multicolumn{4}{|c|}{ Aged living with daughters (100) } \\
\hline \multicolumn{2}{|c|}{ MSEG (50) } & \multicolumn{2}{|c|}{ LSEG (50) } & \multicolumn{2}{|c|}{ MSEG (50) } & \multicolumn{2}{|c|}{ LSEG (50) } \\
\hline M (25) & F (25) & M (25) & F (25) & M (25) & F (25) & M (25) & $\mathrm{F}(25)$ \\
\hline
\end{tabular}

Fig. 1. Sample distribution chart for the study

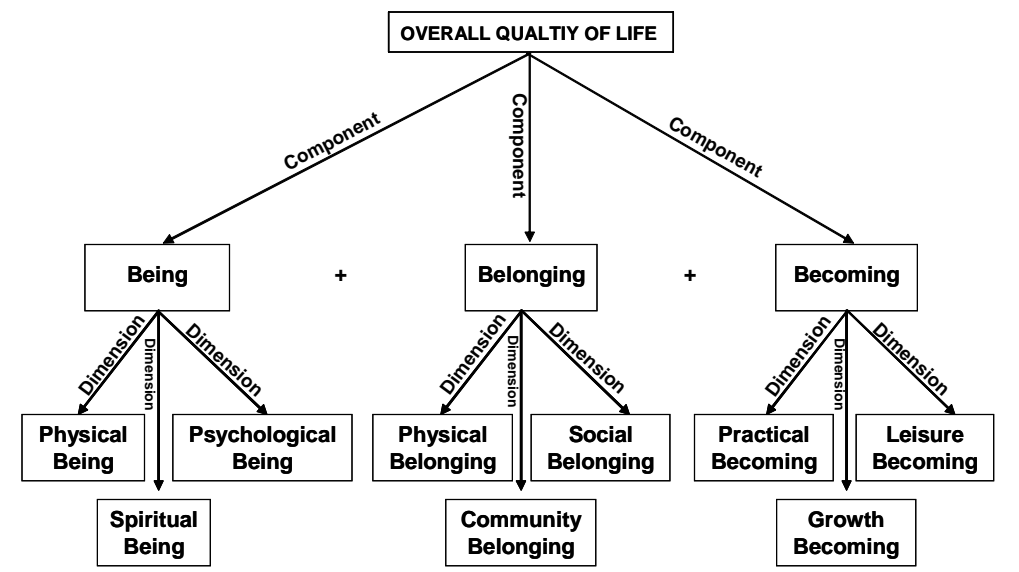

Fig. 2. Components and Dimensions of Overall Quality of Life (QOL) Scroe 
Table 1: Background information of the aged males living with sons and living with daughters

\begin{tabular}{|c|c|c|c|c|}
\hline \multirow{2}{*}{$\begin{array}{l}\text { S. } \\
\text { No. }\end{array}$} & \multirow[t]{2}{*}{ Variable } & \multicolumn{2}{|c|}{ Support system } & \multirow[t]{2}{*}{ Total $(N=100)$} \\
\hline & & $\begin{array}{l}\text { Living with } \\
\text { sons }(n=50)\end{array}$ & $\begin{array}{l}\text { Living with } \\
\text { daughters }(n=50)\end{array}$ & \\
\hline \multirow[t]{4}{*}{1.} & Age (years) & & & \\
\hline & $65-77$ & $38(76.00)$ & $30(60.00)$ & $68(68.00)$ \\
\hline & $77-89$ & $9(18.00)$ & $15(30.00)$ & $24(24.00)$ \\
\hline & 89 and above & $3(6.00)$ & $5(10.00)$ & $8(8.00)$ \\
\hline \multirow[t]{3}{*}{2.} & Socio-economic Status & & & \\
\hline & Low & $25(50.00)$ & $25(50.00)$ & $50(50.00)$ \\
\hline & Middle & $25(50.00)$ & $25(50.00)$ & $50(50.00)$ \\
\hline \multirow[t]{5}{*}{3.} & Education & & & \\
\hline & Under-matric & $24(48.00)$ & $16(32.00)$ & $40(40.00)$ \\
\hline & Matric & $8(16.00)$ & $14(28.00)$ & $22(22.00)$ \\
\hline & Graduate & $9(18.00)$ & $11(22.00)$ & $20(20.00)$ \\
\hline & Post graduate & $9(18.00)$ & $9(18.00)$ & $18(18.00)$ \\
\hline \multirow[t]{5}{*}{4.} & Marital Status & & & \\
\hline & Unmarried & $0(0.00)$ & $0(0.00)$ & $0(0.00)$ \\
\hline & Married (both spouses alive) & $38(76.00)$ & $24(48.00)$ & $62(62.00)$ \\
\hline & Widower & $12(24.00)$ & $26(52.00)$ & $38(38.00)$ \\
\hline & Divorced & $0(0.00)$ & $0(0.00)$ & $0(0.00)$ \\
\hline \multirow[t]{3}{*}{5.} & Living & & & \\
\hline & Without spouse & $6(12.00)$ & $21(42.00)$ & $27(27.00)$ \\
\hline & With spouse & $44(88.00)$ & $29(58.00)$ & $73(73.00)$ \\
\hline \multirow[t]{7}{*}{6.} & Children & & & \\
\hline & No child & $0(0.00)$ & $0(0.00)$ & $0(0.00)$ \\
\hline & Only son & $2(4.00)$ & $0(0.00)$ & $2(2.00)$ \\
\hline & Only daughter & $0(0.00)$ & $5(10.00)$ & $5(5.00)$ \\
\hline & Two or more sons & $7(14.00)$ & $0(0.00)$ & $7(7.00)$ \\
\hline & Two or more daughters & $0(0.00)$ & $13(26.00)$ & $13(13.00)$ \\
\hline & Both son and daughter & $41(82.00)$ & $32(64.00)$ & $73(73.00)$ \\
\hline
\end{tabular}

Figures in parentheses indicate the percentage

age. For the aged Living with sons, majority $(76 \%)$ were in the age group of 65-77 years and only 60 per cent of those Living with daughters fell in this age group. As the age advanced, a higher number of males were found to be "Living with daughters" (30\% and $10 \%)$ rather than sons.

The respondents from both the support systems were almost equally distributed over the two socio-economic levels, namely Middle socio-economic status and Low socio-economic status. Not much variation was noticed in the educational backgrounds of the respondents across both support systems. As regards the literacy levels only 40 per cent male respondents were under-matric and all others $(60 \%)$ were educated beyond matric, that is, 22 per cent were matric, 20 per cent graduates and 18 per cent post-graduates.

It was found that of the male respondents "Living with sons", 36 per cent were graduates and post-graduates and 48 per cent were under matric. Those "Living with daughters", only 21 per cent were graduates and post-grad- uates and majority of them were under-matric (32\%) and matric (28\%).

A probe into the marital status revealed that 76 per cent of the males "Living with the sons" were married (both spouses alive) and those "Living with daughters" included 52 per cent widowers and 48 per cent married (both spouses alive). None among the divorced, aged males were found to be "Living with sons or daughters". Out of the male respondents "Living with daughters", nearly half $(52 \%)$ were widowers, followed by 24 per cent married (both spouses alive). None in the two support systems was unmarried or divorced.

An interesting finding was that males living without spouse had an overwhelming choice $(42 \%)$ of residence with their daughters and only 12 per cent with their sons. The highest proportion of the males with spouses lived with their sons ( $88 \%)$, followed by those Living with their daughters (58\%). Out of the males having both sons and daughters, majority $(82 \%)$ preferred "Living with sons", followed by those 
Table 2: Background information of the aged females living with sons and living with daughters

\begin{tabular}{|c|c|c|c|c|}
\hline \multirow{2}{*}{$\begin{array}{l}S . \\
\text { No. }\end{array}$} & \multirow[t]{2}{*}{ Variable } & \multicolumn{2}{|c|}{ Support system } & \multirow[t]{2}{*}{ Total $(N=100)$} \\
\hline & & $\begin{array}{l}\text { Living with } \\
\text { sons }(n=50)\end{array}$ & $\begin{array}{l}\text { Living with } \\
\text { daughters }(n=50)\end{array}$ & \\
\hline \multirow[t]{4}{*}{1.} & Age (years) & & & \\
\hline & $65-77$ & $35(70.00)$ & $32(64.00)$ & $67(67.00)$ \\
\hline & $77-89$ & $10(20.00)$ & $13(26.00)$ & $23(23.00)$ \\
\hline & 89 and above & $5(10.00)$ & $5(10.00)$ & $10(10.00)$ \\
\hline \multirow[t]{3}{*}{2.} & Socio-economic Status & & & \\
\hline & Low & $25(50.00)$ & $25(50.00)$ & $50(50.00)$ \\
\hline & Middle & $25(50.00)$ & $25(50.00)$ & $50(50.00)$ \\
\hline \multirow[t]{5}{*}{3.} & Education & & & \\
\hline & Under-matric & $30(60.00)$ & $34(68.00)$ & $64(64.00)$ \\
\hline & Matric & $18(36.00)$ & $9(18.00)$ & $27(27.00)$ \\
\hline & Graduate & $2(4.00)$ & $5(10.00)$ & $7(7.00)$ \\
\hline & Post graduate & $0(0.00)$ & $2(4.00)$ & $2(2.00)$ \\
\hline \multirow[t]{5}{*}{4.} & Marital Status & & & \\
\hline & Un married & $0(0.00)$ & $0(0.00)$ & $0(0.00)$ \\
\hline & Married (both spouses alive) & $23(46.00)$ & $17(34.00)$ & $40(40.00)$ \\
\hline & Widower & $27(54.00)$ & $33(66.00)$ & $60(60.00)$ \\
\hline & Divorced & $0(0.00)$ & $0(0.00)$ & $0(0.00)$ \\
\hline \multirow[t]{3}{*}{5.} & Living & & & \\
\hline & Without spouse & $27(54.00)$ & $35(70.00)$ & $62(62.00)$ \\
\hline & With spouse & $23(46.00)$ & $15(30.00)$ & $38(38.00)$ \\
\hline \multirow[t]{7}{*}{6.} & Children & & & \\
\hline & No child & $0(0.00)$ & $0(0.00)$ & $0(0.00)$ \\
\hline & Only son & $4(8.00)$ & $0(0.00)$ & $4(4.00)$ \\
\hline & Only daughter & $0(0.00)$ & $3(6.00)$ & $3(3.00)$ \\
\hline & Two or more sons & $2(4.00)$ & $0(0.00)$ & $2(2.00)$ \\
\hline & Two or more daughters & $0(0.00)$ & $10(20.00)$ & $10(10.00)$ \\
\hline & Both son and daughter & $44(88.00)$ & $37(74.00)$ & $81(81.00)$ \\
\hline
\end{tabular}

Figures in parentheses indicate the percentage

"Living with daughters" (64\%). Thus, living with the sons emerged as the first choice followed by those living with daughters.

Table 2 depicts the background information of female respondents across two support systems with reference to age, education, marital status, living arrangement, i.e. with or without spouse and number of children.

It was found that majority $(67 \%)$ of the female respondents living across two support systems were in the age group of 65-77 years, followed by 23 per cent in the age group of 77-89 years and only 10 per cent exceeding 89 years.

Out of the females living across two support systems, majority (64\%) of them were under-matric, with only a small proportion (7\% and $2 \%$ ) being graduates and post-graduates. It was observed that majority (46\%) of the married (both spouses alive) females lived with sons followed by 34 per cent living with their daughters. Majority of the females were widows $(66 \%)$ and were "Living with daughters" and also 54 per cent of those "Living with sons" were in the same category.
However, the per cent of respondents without spouse "Living with daughters" was quite high (70\%). Of those living with their spouses, majority (46\%) preferred "Living with sons" and remaining 30 per cent "Living with daughters".

Majority of the aged females having both sons and daughters, 88 per cent chose to live with their sons and 74 per cent were living with daughters.

The increasing proportion of older female population is also an important aspect of the public policy as the mortality rates are usually higher among men than women. In fact the percentage of females tends to increase with advancing age. In most of the countries, older women out-number older men. The implications of this gender imbalance for social support and public planning merit serious consideration as older women are mostly widows. They also have less access to public assistance and other private income sources. As such, the concerns of the oldest of old population should be viewed mainly as the concerns of older women (Higuchi 1966, United Nations 1999, United Nations 2002). 
Table 3: Distribution of the aged based on overall Quality of Life (QOL) scores across two support systems $(\mathrm{N}=\mathbf{2 0 0})$

\begin{tabular}{|c|c|c|c|c|c|}
\hline \multirow{2}{*}{$\begin{array}{l}S . \\
\text { No. }\end{array}$} & \multirow[t]{2}{*}{ Category/domain of $Q O L$} & \multirow[t]{2}{*}{ Range of scores } & \multicolumn{2}{|c|}{ Support Systems } & \multirow[t]{2}{*}{$Z$ values } \\
\hline & & & $\begin{array}{l}\text { Living } \\
\text { with sons } \\
(n=100)\end{array}$ & $\begin{array}{l}\text { Living with } \\
\text { daughters } \\
(n=100)\end{array}$ & \\
\hline 1. & Very Good & $>1.50$ & $7(7.00)$ & $4(4.00)$ & 0.93 \\
\hline 2. & Acceptable & 1.50 to 0.51 & $49(49.00)$ & $29(29.00)$ & $2.90 *$ \\
\hline \multicolumn{3}{|c|}{ Positive domain(Very Good +Acceptable ) } & $56(56.00)$ & $33(33.00)$ & $3.27 *$ \\
\hline 3. & Adequate & 0.50 to -0.50 & $42(42.00)$ & $34(34.00)$ & 1.16 \\
\hline \multicolumn{3}{|c|}{ Borderline domain(Adequate) } & $42(42.00)$ & $34(34.00)$ & 1.16 \\
\hline 4. & Problematic & -0.51 to -1.50 & $2(2.00)$ & $31(31.00)$ & $5.53 *$ \\
\hline 5. & Very problematic & $<-1.50$ & $0(0.00)$ & $2(2.00)$ & 1.42 \\
\hline \multicolumn{3}{|c|}{$\begin{array}{l}\text { Negative domain(Problematic }+ \\
\text { Very Problematic) }\end{array}$} & $2(2.00)$ & $33(33.00)$ & $5.77 *$ \\
\hline
\end{tabular}

Figures in parentheses indicate the percentage

* significant at 5 per cent level

Assessment of Quality of Life (QOL) of Aged Living Under Different Support Systems

Table 3 shows the distribution of the aged based on overall Quality of Life (QOL) scores across two support systems selected for this study.

\section{The Three Domains of Quality of Life (QOL)}

The three domains of Quality of Life (QOL), as shown in Table 3, include the Positive, Borderline and Negative domains of Quality of life. Positive domain covered a major share of respondents in the support system "Living with sons", i.e. 56 per cent whereas only 33 per cent from other support system were seen in this domain. "Positive domain" implied good Quality of Life (QOL) at the present time and, thus ought to be sustained and enhanced. The other two categories of Quality of Life (QOL) were the "Borderline domain" and "Negative domain". The second domain i.e., "Borderline domain" refers to the vulnerable category of Quality of Life (QOL), which calls for an action plan to enhance the Quality of Life (QOL). "Negative"the third domain points towards the problem areas that need to be addressed.

\section{Proportion of Respondents in the different Domains of Quality of Life (QOL) Across Selected Support Systems}

1. Positive Domain of Quality of Life (QOL): It is observed from the data presented in Table 3 that the support system comprising 'Living with the sons' had high percentage of the aged falling in the positive domain of Quality of Life (QOL) i.e., 56 per cent. In other words, they were leading Very Good to Acceptable QOL. The data also revealed that for the other support system i.e. 'Living with the daughters', only $33 \%$ of the respondents fell under the positive domain of QOL.

These observations were in line with the ageold Indian traditions, preferences and beliefs. Unless faced with a formidable situation, the aged are known to derive the maximum satisfaction by residing with their sons during their silver age. Most aged in India had strong belief that this was one of their natural choices as it reinforced the age-old Indian tradition and culture. This finding was also supported by other studies inferring that the aged in the traditional societies enjoyed unparallel sense of honour, legitimate authority, and decision-making responsibilities in the family as the elderly were regarded as repositories of experience and wisdom (Khan 1997 and Singh 1997).

2. Adequate or Borderline Domain of Quality of Life (QOL): The second important category of QOL was the 'Adequate' category or 'Borderline' domain of the QOL. It was interesting to observe that the QOL of a fairly large proportion of the aged living under both support systems, namely those 'Living with their sons' (42\%), and those 'Living with their daughters' (34\%) fell under the Borderline domain.

In order to bring about a perceptible change in the existing scenario of this domain (Borderline domain), attention ought to be focused on relevant aspects of Quality of Life (QOL) which might prevent a further slide down of 
the aged,making them vulnerable to slip into the Negative domain of Quality of Life (QOL).

3. Problematic or Negative Domain of Quality of Life (QOL): The third and an equally important segment for the QOL category was the Negative domain inclusive, of both the Problematic and Very Problematic categories of Quality of Life (QOL). It was observed from the data presented in Table 3 that a negligible proportion $(2 \%)$ of the aged 'living with their sons' fell in the negative domain. A very high proportion of the aged in the negative domain were those 'Living with their daughters' (33\%).

The high proportion of respondents reporting Negative Quality of Life (QOL) while living with their daughters is indicative of the unavoidable circumstances and factors that compelled them to adopt this support system. As a matter of fact, either their sons lived at far-off places or the aged people did not feel contented for one reason or the other or they were not fortunate to have a son.

Community Belonging, Leisure Becoming and Growth Becoming were identified as the vulnerable dimensions in both the support systems which need to be upgraded to improve the QOL scores of the aged. These dimensions can be understood and reinforced as discussed below:

Community Belonging refers to the connections with environment. It pertains to the ability of the aged to visit places in the Community, attending special events, access to education and learning, involvement in meaningful work activities, availing medical and social services and having adequate funds to spend.

Leisure Becoming relates to the activities for enjoyment and fun. It involves such items as public entertainment, casual leisure activities (TV, reading, walking, cycling, gardening etc.), organized sports and recreational activities, hobbies, vacations, holidays, trips, visiting and socializing for enjoyment.

Growth Becoming points to adjusting, coping and learning things in Life. It includes coping strategies in Life, improving Physical skills, avenues for learning and adopting new ideas, resolving interpersonal conflicts, solving problems and trying out new things.

These results are inline with the study by Aggarwal (2004) which, states that utilization of senior citizen's potentials to the utmost is essential for making them lead a respectful and satisfactory life along with economic security, old age planning, participation in work, selfless social service and spiritual outlook towards life with optimistic thinking. Retirees who do not have work involvement, proper planning for old age and have pessimistic thinking and are not leading satisfactory retired life. Problems of loneliness, disrespect and of ill-health affect them much. Joint and quassi-nuclear family structures have been found having positive relationship with physical and emotional security in old age provided good adjustment is there among family members. Findings fully support activity theory for satisfactory and graceful ageing.

Ramamurthi and Jamuna (1993b) also observed that self-acceptance of ageing changes, self-perception of health and satisfaction, with marital and familial relations are some of the factors that predict life satisfaction among the elderly and also explain the phenomenon of loneliness.

Chandrashekhar (1993) also suggested that the living conditions and facilities available directly influence the health in old age. Better living conditions and better facilities mean better physical and mental health. Equal opportunities, less competition, social and economical security and stability, love and affection, due respect at this stage helped to minimize stress on the individual.

\section{Comparative Picture of the Two Support Systems by Levels of Quality Of Life (QOL)}

From the above observations it could be concluded that the Positive Quality of Life was being strongly experienced by 56 per cent of the aged 'Living with their sons' whereas the Negative Quality of Life (QOL) was observed in higher proportion in the aged 'Living with their daughters' $(33 \%)$. Therefore, the maximum number of the aged in Problematic Quality of Life (33\%) was of those residing with their daughters. For the aged "Living with daughters" the scores were equally distributed in the three domains of QOL. This reveals the existing mind-set and the inhibitions of the elderly persons to reside with their daughters except under unavoidable circumstances when they were left with no other option.

Biswas (1987) studied dependency and family care of the aged. The study showed that an overwhelming number of the aged lived with their sons. There were very few who decided to live 
Table 4: Comparative analysis of Quality of Life (QOL) of aged across two support systems

\begin{tabular}{lllcc}
\hline S. No. & Support systems & QOL mean scores & $d f$ & t-value \\
\hline 1. & Living with sons $(\mathrm{n}=100)$ & 0.663 & 198 & $5.47 *$ \\
2. & Living with daughters $(\mathrm{n}=100)$ & 0.062 & & \\
\hline
\end{tabular}

*significant at 5 percent level

$\mathrm{df}=$ degree of freedom

with their daughters. Biswas reports, "In substance, therefore sons were the first choice for old age care, and they were often referred to as old age insurance for which property was transferred to them as premium". In the same study, it was pointed out that majority of old women were dissatisfied with the care and service they got (as compared to their male counterparts). As regards the interpersonal relations of the aged with other members of their families, the study found that a majority of them were bound by bonds of reciprocal respect and love, irrespective of complaints about accommodation, food and care. Dissatisfaction was greater among those who were fully dependent on their supporters. It grew keener and bitter with age. Ageing women as a rule were neglected.

\section{Comparative Analysis of Quality of Life (QOL) of Aged Across Different Support Systems}

The data presented in Table 4 depicts the mean scores for the Quality of Life (QOL) across the two support systems.

The higher mean scores were obtained for the aged "Living with their sons" (0.663). But for the aged "Living with their daughters", a very low mean score i.e. 0.062 was obtained. Thus, it could be inferred from this study that "Living with sons" was the most preferred support system for the aged and "Living with the daughters" was the non-preferred support system.

This might be attributed to the fact that Indian culture underpins living of the aged parents with their sons but under normal circumstances living with their daughters is not preferred.

\section{CONCLUSIONS}

Aged living with their sons had a better QOL as most of them enjoyed from 'Very good' to 'Acceptable' QOL. Also a sizeable number of them were placed in 'Borderline' or 'Adequate' category of QOL. The number of the aged in the Problematic QOL category was found to be negligible. In case of the aged living with daughters, the elderly were fairly scattered in all the three domains of QOL. Thus, indicating the vulnerability of this support system to slide into Problematic QOL category.

As ageing of population is becoming more and more pronounced, the concern for the quality of life and well-being of older people is also growing. These years of life are not left over; rather a complete span of life, a stage when like ripened fruit the person is at his best. As the ripened fruit is most flavored, sweet and delicious, so is the person, at this age, most experienced, skilled, talented and wise. The knowledge and experience are matchless, but there is a decline in physical faculties. Thus, the care and QOL becomes an important determinant of the longevity. At this stage certainly the issue is not of adding years to life but that of adding life to the years.

\section{REFERENCES}

Amos OMJ, Hitt MA, Warner L 1992. Life satisfaction and regional development: A case study of Oklahoma. Social Indicators Research, 11: 31931.

Agarwal K 2004. A study of Male Senior Citizens in Urban Setting. Social Welfare, 51(7): 54-59.

Biswas SK 1987. Dependency and Family Care of the Aged. In: SK Biswas (Ed.): Aging in Contemporary India. Calcutta: Indian Anthropological Soc.

Chandrashekhra CR 1993. Mental Disorder of Old Agriculture. Hearld of Health, 83-84: 14.

Delhi School of Social Work 1977. A Study of the Aged in Delhi. (Mimeo), Delhi: University of Delhi.

Higuchi K 1996. Women in an Ageing Society. In Added Years of Life in Asia. Current Situation and Future Challenges. Asian population Studies Series, No. 141 Bankok: Economics Commission for Asia and the Pacific.

Khan MZ 1997. Elderly in Metropolis. New Delhi: Inter-India Publications.

Ramamurti PV, Jamuna D 1993a. Perspectives of GeroPsychology in India: A Review. Indian Psychological Abstracts and Reviews, Volume 2.

Ramamurti PV, Jamuna D 1993b. Some predictors of successful aging satisfaction with present life in an Indian sample. Indian J Gerontology, 3: 6-103.

Soodan KS 1982. Problems of the Aged - Field Study, 
and Implications. In: KG Desai (Ed.): Ageing in India. Bombay: Tata Institute of Social Sciences. Singh Y 1997. Changing trends in the Indian family and the adjustment of the aged. Res Develop J, 3: 31-42.

United Nations 1994. The elderly and the family in developing countries. Occasional Papers Series, No. 13, Vienna: UN

United Nations 2002. World Population Aging: 19502050. Population Division, DESA,
United Nations, 2001. ST/ESA/ SER.A207 (2002). Available from: http//www.un.org/esa/population/ publications/worldageing/19502050/

Vatuk S 1990. "To be a burden on others". Dependency anxiety among the elderly in India. In: Lynch Owen (Ed.): Divine Passions: The Social Construction of Emotion in India. Berkeley: University of California Press. 